\title{
ECOPATIO - UM CAMINHO PARA A SUSTENTABILIDADE
}

\author{
ECOPATIO - UN CAMINO PARA LA SUSTENTABILIDAD
}

\author{
Fabiane de Melo ${ }^{1}$, Jumaida Maria Rosito ${ }^{2}$ \\ 1 Acadêmica do Curso de Especialização em Educação Ambiental da Universidade Federal de Santa Maria (UFSM), RS, \\ Brasil. fabiane-melo-75@hotmail.com \\ 2 Prof. Adjunto do Departamento de Biologia, centro de Ciências Naturais e Exatas da UFSM, RS, Brasil.
}

\section{RESUMO}

Esse trabalho, com início em abril de 2009, teve por principal objetivo repensar o ambiente escolar das escolas municipais de Ensino Fundamental, localizadas na zona urbana do Município de Araricá, na região leste do estado do Rio Grande do Sul (Brasil). A seleção das escolas que deveriam compor a amostra foi feita com o apoio da Escola Ambiental "Espaço Sementes da Vida" e da Secretaria de Educação do município, através da avaliação dos projetos apresentados pelas escolas participantes do Concurso "Ecopátio". A idéia do projeto era de que as instituições de ensino repensassem o pátio da escola, criando meios sustentáveis para redesenhar o ambiente, bem como repensassem o termo "lixo", modificando seu uso. As escolas foram avaliadas por uma comissão composta por diferentes segmentos da sociedade que visitou o ambiente escolar para verificar a execução das ações propostas. A metodologia utilizada permitiu a implantação de um processo coletivo de produção e troca de saberes, proporcionando uma ação educativa interdisciplinar em toda a comunidade escolar, possibilitando a ecoalfabetização de alunos, professores e funcionários.

Palavras-chave: meio ambiente; desenvolvimento sustentável; educação ambiental; ecoalfabetização; comunidade escolar.

\section{RESUMEN}

Ese trabajo, empezó en abril de 2009, tuve por principal objetivo repensar el ambiente escolar de las escuelas municipales de Enseñanza Fundamental, localizadas en el sitio urbano de la ciudad de Araricá, en la región leste del estado del Rio Grande del Sur (Brasil). La selección de las escuelas que deberían componer la amostra fue realizada con el apoyo de la Escuela Ambiental "Espacios Semientes de la Vida" y de la Secretaria de Educación de la ciudad, a través de la evaluación de los proyectos presentados por las escuelas participantes del Concurso "Ecopatio". La idea del proyecto era de que las instituciones de enseñanza repensasen el patio de la escuela, creando medios sustentables para redibujar el ambiente, bien como repensaren el termo "basura", cambiando su uso. Las escuelas fueron valoradas por una delegación compuesta por distintos segmentos de la sociedad y que visitó el ambiente escolar para constatar la elaboración de las acciones propuestas. La metodología usada permitió la implantación de un proceso colectivo de producción y cambio de saberes, proporcionando una acción educativa interdisciplinar en todo la comunidad escolar, posibilitando la ecoalfabetización de alumnos, 
profesores y funcionarios.

Palabras-llaves: médio ambiente; desenvolvimiento sustentable; educación ambiental; ecoalfabetización; comunidad escolar.

\section{INTRODUÇÃO}

Segundo Legan (2004), "a definição mais apropriada diz que o sistema em que vivemos deve satisfazer nossas necessidades de crescimento e manutenção e o excedente deve ser utilizado para re- investimento", ou seja, o foco deve ser em satisfazer nossas necessidades do presente sem comprometer a capacidade das futuras gerações de satisfazerem as suas. Mas, talvez, o maior entrave para a solução da crise ambiental que nos assombra nas últimas décadas, seja a crença de que, sozinhos, não causamos danos nem fazemos a diferença. A Educação Ambiental (EA) vem sendo valorizada como uma ação educativa que deveria estar presente, de forma transversal e interdisciplinar, articulando o conjunto de saberes, formação de atitudes e sensibilidades ambientais (CARVALHO, 2004); inserida no contexto escolar, ela leva a comunidade a refletir questões que envolvem a vida no planeta. É um processo de formação e informação orientado para o desenvolvimento da consciência crítica sobre as questões ambientais, e de atividades que levem à participação das comunidades na preservação do equilíbrio ambiental (CONAMA, resolução n.o 10/93, 1993). Segundo Carvalho, (1998), a Educação Ambiental passou a se inserir na sociedade brasileira, de modo extra-oficial, a partir da década de 70. A Educação Ambiental (EA) vem sendo valorizada como uma ação educativa que deveria estar presente, de forma transversal e interdisciplinar, articulando o conjunto de saberes, formação de atitudes e sensibilidades ambientais (CARVALHO, 2004).

Tal processo educativo pode contribuir para que ocorram modificações profundas no comportamento humano, que estão ligadas aos valores, aos comportamentos, às atitudes e à própria ética (Nunes, 2005).

A Agenda 21, elaborada durante a Conferência das Nações Unidas sobre o Meio Ambiente e Desenvolvimento, realizada no Rio de Janeiro no ano de 1992, destacou que, para ser eficaz, o ensino sobre o meio ambiente deve propor um trabalho interdisciplinar com a utilização de métodos formais e não formais e meios efetivos de comunicação (AGENDA 21, 1992). Porém, na questão Educação ambiental x Educação formal, a maior dificuldade é a de agregar os segmentos da comunidade escolar em torno das questões ambientais. Professores e funcionários devem ser vistos como norteadores na questão da preservação e sustentabilidade, já que os alunos aprendem com exemplos.

Para Fedrizzi (1999), não adianta falarmos sobre ecologia em uma escola que apresenta seu pátio descuidado e sem vegetação, e que algumas pesquisas têm demonstrado o quanto melhora a capacidade de concentração das crianças quando elas têm maior contato com a natureza. $\mathrm{O}$ autor vê o pátio escolar como um importante recurso educacional, o qual pode promover aprendizagem, curiosidade, responsabilidade e respeito pela natureza.

No município de Araricá (RS), desde 2005, funciona uma escola ambiental que se denomina "Espaço Sementes da Vida", que atende as escolas da rede municipal, estadual e privada. A Escola tem como principal objetivo a ecoalfabetização; ela oportuniza, também, oficinas para a 
comunidade, professores e funcionários, além de desenvolver projetos com a Secretaria da Saúde. A prática demonstrou que esses encontros são proveitosos, mas que não há uma ligação e continuidade entre as atividades realizadas na escola ambiental e a escola formal; isso, aparentemente, leva a um arrefecimento do entusiasmo dos alunos com as questões ambientais. Esse trabalho surgiu a partir da idéia de dar continuidade às atividades e questionamentos plantados pela Escola Ambiental. Nasce, assim, o projeto "Ecopátio", que tem como principal objetivo o repensar do pátio escolar, criando meios sustentáveis para redesenhar o ambiente e repensar o termo "lixo", modificando seu uso, nas escolas municipais de Ensino Fundamental, localizadas na zona urbana do Município de Araricá, ou seja,

Ensinar os princípios básicos de ecologia necessários para planejar comunidades humanas sustentáveis e compatíveis com os processos naturais, assim como o respeito pela natureza viva por meio de uma abordagem multidisciplinar baseada na experiência e na participação (CAPRA, 2006).

O projeto Ecopátio está comprometido com a criação de relações entre a EA em todas as disciplinas, com as ações criadas e executadas pela comunidade escolar no pátio da escola, integrando homem e natureza. Segundo Gadotti (2003), "todas as nossas escolas podem transformar-se em jardins e professores-alunos, educadores-educandos, em jardineiros.

\section{MATERIAIS E MÉTODOS}

A seleção das escolas municipais para comporem a amostra e a realização desta pesquisa foi feita com o apoio da Escola Ambiental Espaço Sementes da Vida e da Secretaria de Educação do município de Araricá, através dos projetos de reformulação do pátio escolar apresentados para o Concurso Ecopátio. A partir daí, identificou-se os projetos que foram apresentados pelas Escolas Municipais de Ensino Fundamental, localizadas na zona urbana da cidade de Araricá.

O projeto Ecopátio iniciou em abril de 2009 e foi primeiramente apresentado aos diretores e pedagogos das três Escolas Municipais de Ensino Fundamental. Para preservar a identidade das escolas, estas foram identificadas, no presente trabalho, como escolas Macela, Camomila e Hortelã.

A execução dos trabalhos seguiu as seguintes etapas:

1 a etapa - seleção e análise do material bibliográfico disponível para a elaboração do referencial teórico a ser adotado na pesquisa.

2a etapa - contato com a Escola Ambiental Espaço Sementes da Vida e Secretaria da Educação de Araricá para parceria na execução do projeto e coleta de dados.

3a etapa - busca de parcerias para formar uma comissão julgadora do concurso Ecopátio e também para a premiação do mesmo. Em seguida foi apresentada a Comissão dos Avaliadores, que foram convidados pela Escola Ambiental e Secretaria da Educação.

A comissão foi constituída pelos seguintes membros: um agrônomo do município de Araricá, uma bióloga do município de Sapiranga, um vereador do município de Araricá, um representante da Associação dos Agricultores Municipais, um representante da Emater de Sapiranga e um representante da imprensa da regional de Nova Hartz.

4a etapa - apresentação dos projetos das três Escolas Municipais de Ensino Fundamental de 
Araricá demonstrando ações pretendidas pelos guias. Cada escola deveria escolher e preparar alunos- guias que iriam apresentar o projeto da escola e guiar os avaliadores durante as visitas que iriam ocorrer durante o ano. Dessa forma, no IV Seminário do Meio Ambiente, no início do mês de junho, cada guia apresentou as ações que a escola pretendia desenvolver durante o ano.

5a etapa - verificação e constatação do desenvolvimento das ações pretendidas nos projetos apresentados pelas três escolas participantes. A primeira visita aos Ecopátios ocorreu no mês de junho. Os avaliadores receberam a planilha 1 (apêndice A) para registrar tanto seus pareceres descritivos quanto para marcar a pontuação de dois a dez de cada escola. Decidiu-se iniciar a pontuação a partir de dois pontos, pois o fato de cada escola estar participando do projeto já foi considerado um ponto positivo conquistando assim o primeiro ponto. As planilhas e o logotipo do projeto foram criados a partir de sugestões dos parceiros coordenadores da Escola Ambiental e da Secretaria de Educação Municipal. As cores do logotipo foram escolhidas pensando-se na cor verde representando a Escola Ambiental Sementes Espaços da vida assim estaria sendo representada a natureza e no lilás por ser uma das cores do logotipo da Secretaria da Educação. A visita deveria ser dirigida por alunos-guia e não por professores e equipe diretiva, justamente para que acontecesse a maior interação possível dos alunos com o projeto.

Ocorreu no mês de novembro de 2009, a segunda e última visita aos Ecopátios. Os avaliadores receberam a planilha 2 (apêndice $B$ ) para registrar tanto seus pareceres descritivos e marcar a pontuação de zero a dez de cada escola, observando o desenvolvimento das ações pretendidas no início do projeto e a execução destas na escola. Os pátios escolares foram avaliados, também, pelos elementos artísticos, estéticos, funcionais e pedagógicos criados por cada escola. Os critérios de avaliação foram: Uso dos 5R"s (reciclar, reduzir, reutilizar, repensar e relacionar); aproveitamento do espaço; organização; espaço verde; dicionário de plantas; criatividade; harmonia e guias.

Os resultados dessas visitas servirão para análise dos resultados do projeto.

6a etapa - premiação da escola modelo do concurso Ecopátio. Na IV Mostra Multicultural, em dezembro de 2009 foram realizadas as apresentações dos Ecopátios pelas escolas Camomila e Hortelã e a conclusão dos projetos com a premiação da escola modelo. Somente uma escola foi premiada com o valor de $\mathrm{R} \$ 300,00$, eleita pela Comissão de Avaliação. O prêmio foi doado pela Câmara de Vereadores.

A escola Macela apresentou justificativa pela não conclusão do projeto (apêndice $G$ ).

7ạ etapa - realização de uma análise qualitativa e quantitativa dos dados obtidos na planilha de avaliação e nos questionários.

8a etapa - discussão dos resultados. Para finalizar encaminhou-se às escolas Camomila e Hortelã, que concluíram o projeto, um questionário para alunos (apêndices D e F) e outro para equipe diretiva (apêndices $\mathrm{C}$ e E), que elaborado com o objetivo de avaliar o desenvolvimento do projeto na escola e, a partir deste questionário, analisar pontos negativos e positivos na execução seu alcance em relação ao tema proposto: repensar o pátio da escola, criando meios sustentáveis para redesenhar a formação do ambiente, bem como repensar o termo "lixo" modificando seu uso.

\section{RESULTADOS E DISCUSSÃO}

Constatou-se pela avaliação da equipe diretiva da escola Hortelã, que a escola, como um todo, refletiu sobre o uso concreto da palavra sustentabilidade e que, a partir dessa reflexão, a 


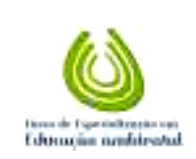

MELO \& ROSITO, vol.(4), n4, p. 786-792, 2011. Monografias Ambientais

(e-ISSN: 2236-1308)

REMOA

comunidade pensou em ações sustentáveis a serem executadas na escola. Uma vez que houve a participação de todos os segmentos (professores, funcionários, alunos e comunidade em geral), a escola conseguiu concluir todas as ações planejadas.

Os alunos-guia foram escolhidos pela participação, interesse, contribuição de idéias, presença nos dias combinados para trabalho no Ecopátio e o entendimento dessas ações realizadas. Pelo envolvimento de todos, não encontraram dificuldades na execução do projeto. $E$, assim, a direção concluiu que a EA está no dia a dia de nossa vida, que pode ser abordada em todas as aulas através de projetos e experiências de vida, tornando-se uma questão interdisciplinar.

Fica comprovado aqui que a responsabilidade de se tratar das questões ambientais não pode pairar apenas no professor e na disciplina de ciências, como ainda pensam muitos professores. Mas com certeza esta escola conseguiu aproximar está visão de união, do todo, da interdisciplinaridade.

De acordo com o relato da equipe diretiva da escola Camomila, foram muitas as ações planejadas; cada professor ficou responsável junto a sua turma com o comprometimento de determinadas ações. Mesmo assim, foram poucas as concretizadas; isso foi justificado pelo clima (muitos dias chuvosos nos meses de agosto e setembro), prorrogação do recesso escolar em agosto por motivo da Influenza $\mathrm{H}^{1} \mathrm{~N}^{1}$, dificultando assim o engajamento dos professores e da direção na execução das ações previstas. Foi citada, ainda, a falta de mobilização da comunidade. Os alunos-guia foram escolhidos pela boa comunicação, participação e o gosto pela temática ambiental. Pelos resultados analisados, o envolvimento da escola foi efetivo somente em algumas turmas e pelo relato, as atividades eram feitas somente no período de aula. $\mathrm{E}$ assim a direção percebeu que a EA pode e deve ser trabalhada em todas as disciplinas, prevendo ações interdisciplinares. A escola deve estabelecer metas a serem alcançadas por todos (professores, alunos e direção) visando uma educação para o desenvolvimento sustentável.

De acordo com a análise dos dois relatos, das escolas Hortelã e Camomila, a escola Hortelã atingiu todos os seus objetivos durante o projeto Ecopátio, pois teve o estímulo da direção e o engajamento dos professores e, foi clara a motivação dos alunos na execução das ações. Já na escola Camomila, a maioria dos objetivos não foi alcançado; houve mais justificativas do que determinação em desenvolver o projeto na escola, pela falta de motivação de professores e da equipe diretiva, como foi afirmado na avaliação; os alunos consequentemente, não foram contagiados a viver a transformação do ambiente escolar. Mas o que ficou registrado de positivo foi que a escola observou suas falhas e acredita na EA como ações interdisciplinares e irá buscar sanar as dificuldades encontradas.

Quanto ao levantamento de dados coletados por meio do questionário dos dez alunos da escola Hortelã (um de 2ạ série, um de $5^{a}$ série, cinco de 6a série, um de 7ạ série e dois de 8a série), foi constatado que a maioria estuda na escola há mais de seis anos. Na visão deles, o pátio da escola era sem vida, com poucas plantas e flores e com lixo espalhado. Após a reformulação, o ambiente escolar ficou mais alegre, bonito e aconchegante, todos deram mais valor e zelo ao pátio; passaram a usar a sala verde para conversar, aprender e também se sentiram valorizados, contribuindo com idéias e vê-las sendo concretizadas.

A comunidade teve participação no projeto fazendo doações de materiais (mudas, esterco, madeira, ferramentas) e mão de obra. Em troca, a escola ofereceu à comunidade vassouras, confeccionadas de garrafas pet por alguns alunos da própria escola. Em geral, foram muitas as contribuições dos alunos na execução do projeto como: preservação do pátio, separação do lixo, plantação de várias espécies vegetais, capina, limpeza, pintura de tela, conserto de postes, latas, transferência da pracinha de local, construção da ponte ecológica (como 
chamam), confecções de trabalhos artísticos com reutilização de alguns materiais e contribuição com tantas idéias.

Através do questionário dos dez alunos da escola Camomila (quatro de 5 a série, dois de 6a série,

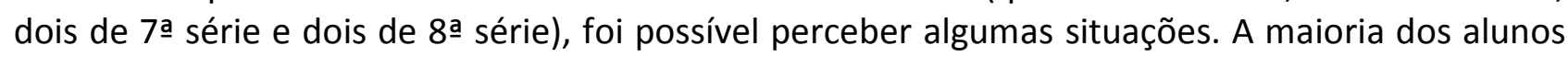
estuda há mais de cinco anos na escola; para eles a visão do pátio da escola era de poucos canteiros e bancos, plantas sem vida e grama alta e, após a reformulação do ambiente escolar, obtiveram mais canteiros, plantas e flores, mais bancos, pintaram pneus para utilizarem na ornamentação dos canteiros. Alguns alunos relacionaram itens fora do contexto do projeto Ecopátio como sala de informática, biblioteca, passarela coberta, que são aquisições feitas através da Secretaria de Educação, não feitas em função do projeto. A comunidade teve participação mínima, ajudando somente na arrecadação do óleo de cozinha para confecção de sabão.

A contribuição da maioria dos alunos na execução do projeto foi na construção de canteiros, revitalização da horta, limpeza do pátio, capina, pintura de pneus, conscientização de parentes e vizinhos da importância da reutilização de materiais. E alguns alunos disseram não participar.

Ficou claro que os alunos da escola Hortelã estavam bem mais motivados e levaram o projeto a sério, contribuindo na execução das ações planejadas. Após o término da reformulação do pátio escolar aprovaram o resultado, aproveitando cada espaço construído com os colegas e professores. Já os alunos da escola Camomila pareciam estar pouco informados sobre os objetivos do Ecopátio, não houve muita troca de idéias, realizaram algumas ações, praticamente reativaram o que já tinham no ambiente escolar. A novidade foi a utilização dos pneus coloridos e a campanha da reutilização do óleo de cozinha em sabão.

Na escola Macela, na segunda visita realizada, a diretora da escola recebeu os avaliadores na sala dos professores e explicou à comissão de avaliação que a escola por decisão da maioria dos professores e funcionários, interromperam o projeto Ecopátio na escola, alegando a m udança para um novo prédio que estava sendo construído ao lado do prédio atual, entregando aos avaliadores a justificativa em forma de ofício. Mas a escola segundo a diretora irá participar do Ecopátio em 2010, pois todos ficaram motivados a realizarem as ações planejadas para reformulação do pátio escolar.

\section{CONCLUSÃO E CONSIDERAÇÕES FINAIS}

A metodologia utilizada permitiu a implantação de um processo coletivo de produção e troca de saberes, proporcionando uma ação educativa interdisciplinar que envolveu toda a comunidade escolar, possibilitando a interação de alunos, professores e funcionários para repensar o ambiente escolar em meios sustentáveis, a reutilização de materiais, a união de todos nas questões ambientais, além do estímulo a ações e reflexões, conduziram à transformação do pátio escolar e de muitos valores dentro das escolas.

O Ecopátio - vida no pátio - vida que foi reconstruída no pátio escolar por muitos que, sem a exata noção disso, também queriam um novo começo, e mostraram isso em cada ação realizada no ambiente escolar. Vida que ultrapassou o pátio escolar, foi muito além, internalizou novas esperanças, contagiou a comunidade, a comissão de avaliadores, os parceiros Espaço Sementes da Vida, a Secretaria de Educação e principalmente a mim ao ver tantas modificações realizadas através desse projeto. A Educação Ambiental foi trabalhada de forma interdisciplinar, percebe-se pelo trabalho em equipe e pela conversão dos valores do homem com a natureza. Cada um precisa fazer a sua parte para que juntos vivam numa sociedade ecologicamente correta. 
O sucesso deste projeto foi possível graças à relação de comprometimento entre direção escolar, professores, funcionários e sobretudo o envolvimento dos alunos. O município de Araricá vem trabalhando constantemente a educação ambiental com toda comunidade. Sabe-se que este trabalho exige persistência para formar cidadãos mais conscientes no futuro. Atualmente, todos os trabalhos que abordam as questões ambientais têm como referência a Escola Ambiental "Espaço Sementes da Vida" e, a partir de agora, os Ecopátios. Ambos são modelos e referências para a comunidade escolar, sempre que pretende entender, realizar ou questionar alguma ação ambiental. Estes locais são para o município as „bibliotecas verdes", pelas quais, todos alunos, professores, diretores, funcionários e pais, são os responsáveis.

Desde que conduzido de forma pedagógica e questionadora, o ecopátio pode estimular o surgimento de novas iniciativas que complementem e fortaleçam a atuação da comunidade em questões ambientais.

\section{AGRADECIMENTOS}

Agradeço a minha orientadora, professora Jumaida Maria Rosito.

Agradeço à UFSM, por proporcionar a oportunidade de estudar, através do convênio com o Pólo de Sapiranga-RS.

Agradeço ao Espaço Sementes da Vida, por me mostrar caminhos mais verdes em minha vida.

\section{REFERÊNCIAS BIBLIOGRÁFICAS}

AGENDA 21. Conferência das Nações Unidas sobre o meio ambiente e desenvolvimento. Rio de Janeiro, \{S. Ed.\} 1992, cap.36.

CAPRA, Fritjof. Alfabetização ecológica: a educação das crianças para um mundo sustentável. São Paulo: Cultrix, 2006.

CARVALHO, I.C. As transformações na cultura e o debate ecológico: desafios políticos para a educação ambiental. In: Noal, F. REIGOTA, M.; BARCELOS, V. (org.) Tendências da Educação Ambiental Brasileira. Santa Cruz do Sul: EDUNISC, 1998.

CARVALHO, Isabel Cristina de Moura. Educação Ambiental: a formação do sujeito ecológico. São Paulo: Cortez, 2004.

CONAMA. Conselho Nacional do Meio Ambiente. Resolução n. 10/93. Brasília: 1993.

FEDRIZZI, B. Paisagismo no pátio escolar. Porto Alegre: Editora da Universidade/ UFRGS, 1999.

GADOTTI, Moacir. Boniteza de um sonho: ensinar-e-aprender com sentido. Novo Hamburgo: Feevale, 2003.

LEGAN, Lucia. A escola sustentável: eco-alfabetizando pelo ambiente. São Paulo: Imprensa Oficial do Estado de São Paulo; Pirenópolis, GO: IPEC - Instituto de Permacultura e Ecovilas do Cerrado, 2004.

NUNES, Ellen Regina Mayhé. Alfabetização ecológica: um caminho para a sustentabilidade. Porto Alegre: Ed. Do Autor, 2005. 